\title{
Tolerância, coragem e compaixão: virtudes cardinais do cirurgião
}

\section{Tolerance, courage and compassion: cardinal virtues of the surgeon}

\author{
Cleber Soares Júnior, tCBC - MG'; Carlos Augusto Gomes, tCBC - MG²; Rodrigo de Oliveira Peixoto3; Fernanda Pardo de \\ Toledo Piza Soares ${ }^{4}$
}

RE S U M O

\begin{abstract}
As interações entre os seres humanos são muito complexas. A abordagem de um conflito moral utilizando apenas como referencial um código de ética é quase sempre insuficiente. A ética da responsabilidade demanda uma reflexão muito mais profunda, uma discussão sobre a essência do homem e seu papel na sociedade. A responsabilidade do cirurgião é inerente a uma profissão construída desde sua origem não somente sobre o altruísmo e a humanidade, mas também compaixão, coragem e tolerância. $\mathrm{O}$ estudo e a compreensão destas qualidades, assim como a transmissão destes valores aos alunos e residentes de cirurgia são fundamentais para formação humana destes indivíduos. Este ensaio se propõe a mostrar que estas virtudes essenciais estão indissoluvelmente ligadas ao trabalho que o cirurgião faz, conquanto sua responsabilidade se inicia antes do ato operatório, já na intenção de agir.
\end{abstract}

Descritores: Educação médica. Códigos de ética. Personalidade. Moral. Virtudes.

\section{INTRODUÇÃO}

$\mathrm{O}$ melhores cirurgiões reconhecem as limitações da tecnologia, da ciência e do talento humano. Entretanto, não admitem limites para a busca pela verdade, não admitem imposições, não se esquivam da possibilidade do erro. Este decorre da enorme capacidade de pensar e agir a que se submetem, e da necessidade de agir intuitivamente em determinadas situações ${ }^{1,2}$. Os cirurgiões vivem num mundo à parte, à margem do cotidiano. Supõese que sejam mais fortes, controlados e impassíveis, capazes de suportar o desgaste físico e psicológico. Seria pretensão ter certeza de que se comportam desta forma, mas, em verdade, pode-se pensar que eles refletem estas características nas pessoas, e que, de certa forma, é bom que seja assim. De fato, são a coragem, tolerância e a compaixão que eles demonstram de uma maneira peculiar, própria da profissão, que são confundidas com arrogância, empáfia e impiedade. Uma visão mais detalhada daquelas virtudes é essencial para compreensão das atitudes dos cirurgiões, e para o entendimento de que o ato de operar exige que o médico desenvolva estas qualidades e valores indispensáveis à profissão.

\section{Tolerância}

O vocábulo tolerância deriva do latim tolerare, e significa sofrer, suportar, mas também combater. Na ver- dade ele nos reporta a uma condição assimétrica, no qual alguém tem posição superior a outrem.

Nenhum cirurgião concordará que simplesmente aceitem seus fracassos e tolerem seus erros.

" $O$ direito ao erro somente existe até a demonstração do mesmo, não autoriza persistir nele, nem dá direito algum" ${ }^{3}$. Por isso a cirurgia é mais ciência que arte, já que esta não permite correção. Não obstante, a ciência só se desenvolve corrigindo seus erros. As pesquisas se encarregam de modificar os dogmas, de corrigir as teorias, de alterar conclusões, de simplificar quando possível, e de tornar complexo quando necessário. É por isso que a tolerância tem seu lugar.

O cirurgião lida com incertezas, destarte tolerar deve fazer parte de seu caráter. Não a tolerância do erro puro e simples, não com sentido de resignação ou indiferença, mas como respeito e prudência. Infelizmente, o cirurgião é confundido como arrogante e autoritário. Engana-se quem pensa desta forma. Em decorrência da imprecisão com que lida, ele necessita ser mais tolerante para "renunciar a parte de seu poder, de sua força, de sua cóle$\mathrm{ra}^{\prime 3}$.

A medicina e a cirurgia são, de certa forma, perturbadoras, os riscos que aceitamos são altos. Atul Gawande, muito apropriadamente, nos diz que "quando chegamos bem perto, o que encontramos são cenhos franzidos, dúvidas e passos errados (...) os limites nos quais a

Trabalho realizado no Hospital Universitário da Faculdade de Medicina da Universidade Federal de Juiz de Fora-MG-BR.

1. Supervisor do Programa de Residencia Médica em Cirurgia Geral do Hospital Therezinha de Jesus da Faculdade de Ciências Médicas de Juiz de Fora. Mestre em Cirurgia-MG-BR; 2. Professor Doutor da Disciplina de Cirurgia Gastroenterológica da Faculdade de Medicina da Universidade Federal de Juiz de Fora (UFJF) -MG-BR; 3. Professor Mestre da Disciplina de Cirurgia Gastroenterológica da Faculdade de Medicina da Universidade Federal de Juiz de Fora (UFJF) -MG-BR; 4. Professora Mestre da Faculdade de Nutrição da Universidade Presidente Antônio Carlos / Juiz de Fora (MG)- MG-BR. 
nossa arte se revela em seu limite, desordenada e surpreendente" ${ }^{4}$. Trabalho duro e padrões altos de excelência são exigidos de todos os cirurgiões, pois a vida de cada paciente é valiosa, e os deslizes e quedas são irreparáveis.

A natureza do trabalho do cirurgião também o incita a responsabilizar-se por seus atos e pelas consequências destes. Tolerar é se responsabilizar. Em ciência este é um fato importante: ter o acesso ao conhecimento não autoriza ninguém a forçá-lo aos outros. Mesmo que soubéssemos toda a verdade, não estaríamos autorizados a impô-la, pois assim como "a verdade não obedece, o conhecimento não julga, nem comanda" ${ }^{3}$.

Não é um caso simples de perdoar-nos reciprocamente, é preciso mais. É preciso superação da inveja, do nosso próprio interesse, de nossa impaciência e sofrimento. Não há tolerância quando nada se tem a perder³. $O$ verdadeiro não é o bem comum, o conhecimento nem sempre é capaz de estimular a vontade, o desejo da verdade não é igual para todos.

Marcelo Gleiser está correto quando diz que "a ciência precisa de liberdade para progredir. É difícil imaginar que idéias possam fluir em uma realidade cheia de obstáculos morais e censuras legislativas. A censura e a rigidez moral castram a criatividade (tão importante para o cirurgião), mas não conseguem destruí-la" ${ }^{5}$.

A tolerância ocupa uma posição intermediária entre as grandes virtudes, que são a justiça, coragem, prudência e temperança, e as pequenas virtudes como a polidez e a inocência. De forma alguma corresponde a um ato passivo. Tolerar é um ato permanente de educação dos outros e de si mesmo, mas que exige ação contra todo tipo de repressão, opressão e discriminação.

A história mostra o que ocorre quando se ama mais a certeza que a verdade, quando o conhecimento governa sem sabedoria, quando quem comanda pensa que pode desvirtuar a verdade, subjulgá-la e modificála; mas a verdade não obedece a ninguém. "Somos todos feitos de fraquezas e de erros; perdoemo-nos reciprocamente nossas tolices" ${ }^{\prime 2}$. Assim é o conhecimento médicocirúrgico: imperfeito, desordenado e em modificação constante, feito "de informações incertas, de indivíduos falíveis, de vidas em risco" 4 .

A formação cirúrgica, assim como, médica deve estar embasada em: aprender a conhecer; aprender a compartilhar o conhecimento; aprender a fazer (e quando); aprender a viver em comunidade; aprender a ser e aprender a tolerar. A tolerância demanda que os fatores anteriores estejam presentes, que tenham sido introjetados, que estejam sendo aplicados, que tenham sido compreendidos.

De certa forma, o cirurgião é como Prometeu acorrentado ao Cáucaso, orgulhoso de suas vitórias, mas conhecedor de suas limitações e fracassos. Ele se orgulha daquilo que é, e daquilo que faz em prol do paciente ${ }^{6}$. "Titã, a cujos olhos imortais / As dores dos mortais / Mostram-se em sua crua realidade, / Como algo que os própri- os deuses vêem/, Que prêmio mereceu tua piedade? I Um profundo e silente sofrimento, / O abutre, a corrente, a rocha, / E o orgulho de sofrer sem um lamento".

\section{Coragem}

A "nossa vida desperta o nosso caráter. Você descobre mais a respeito de você mesmo à medida que vai em frente. Por isso é bom estar apto a se colocar em situações que despertem o mais elevado (sentimento) e não o mais baixo da natureza"7. É, sobretudo, preciso coragem para seguir em frente quando se pode recuar, para persistir quando se pode desistir. Não apenas pelo prazer da disputa, mas pela beleza de proporcionar ao nosso caráter um desafio, cujos beneficiados somos nós e nossos pacientes. As pessoas verdadeiramente corajosas o são pela beleza do ato, pelo gesto, e nada mais ${ }^{3}$.

A vida de um cirurgião exige coragem. Ela inclui certa "insensibilidade" ao medo, mas isto não é um pressuposto ${ }^{3}$. A capacidade de superá-lo, de dominá-lo, é que exige uma vontade mais forte, e cada desafio que não os derrota, torna-os ainda mais fortes. A coragem encanta e inspira histórias, é a virtude dos cirurgiões.

A coragem é a virtude mais admirada, não como bravura, menos ainda como um espetáculo. 0 que estimamos na coragem é o risco aceito e corrido, mas também o desapego e o desprendimento. Ela somente é estimável quando se põe a serviço de outrem, quando escapa do interesse, quando é generosa. O medo e a covardia são egoístas" ${ }^{3}$.

Uma disposição para a coragem pode ser encontrada na Oração do Médico (1793), escrita por Maimônides e traz: "Concede-me força de coração e de mente, para que ambos possam estar prontos..."; e também em: "fazei com que eu seja moderado em tudo, mas insaciável em meu amor pela ciência"8. A busca pela verdade exige coragem !

Neste contexto pode-se discordar de ComteSponvile ${ }^{3}$ quando este diz que a ciência nunca deu coragem a ninguém e que a razão não tem medo. O conhecimento multiplica a coragem. A ciência transforma uma atitude temerária nesta virtude. Ela retira os homens da apatia. Ela os estimula, os ilumina, cria condições para que medos verdadeiros e não superstições e fanatismo sejam o foco das atenções. O conhecimento coloca realidade no mundo e somente sentem medos ilusórios aqueles à margem do progresso científico ou os insanos. A razão tem medo sim ! Um medo controlado, não um pavor desmedido. Nas palavras de Claude Bernard: "a ciência aumenta nossa potência e diminui o nosso orgulho" 9 .

Quando há uma operação indicada num paciente muito grave, ponderamos se o melhor é submetê-lo ao risco ou não. Comte-Sponvile citando Jankélévitch afirma que "o raciocínio nos diz o que devemos fazer, se o devemos, mas não nos diz que devemos fazê-lo" ${ }^{3}$. Pelo contrário, a razão é que diz que devemos fazer determinado trabalho, ou ter determinada atitude. Não operar pelo ris- 
co imposto pelas morbidezes presentes, também é mérito da razão. Temos medo de não curar o paciente e temos medo de que ele venha a falecer durante o procedimento. A razão se amedronta dentro da realidade imposta. Seus limites não são iguais aos dos mitos e lendas, e muito menos similares aos dos não esclarecidos. Seus limites são o certo e o errado, dentro da esfera do conhecimento médico. Entretanto, é preciso concordar com Sponvile quando diz que a razão e a verdade não são suficientes, ainda é preciso superar os riscos para atingir os objetivos ${ }^{3}$, e, por isso, a coragem é tão importante para o cirurgião, já que ela é constitída basicamente de vontade.

Talvez não haja na Medicina outra especialidade que demande mais desta qualidade que a cirurgia. $\mathrm{Dr}$. Harold Ellis, professor da Universidade de Edimburgo, cita que, na ânsia de responder a pergunta "O que constitui uma cirurgia histórica ?" precisou classificar o assunto em três categorias: tipo I, cirurgias que reconhecidamente marcaram sua época em virtude do avanço que proporcionaram; tipo II, aquelas operações que são insignificantes em si mesma, mas adicionam um passo técnico novo no que tange ao tratamento; tipo III, cirurgias realizadas sobre pacientes ilustres, mesmo que a cirurgia não tenha nenhuma novidade técnica ${ }^{10}$.

Podemos dizer que um cirurgião que esteja incluído em qualquer destes tipos deve ser portador de uma coragem incomum. Não nos referimos ao cirurgião imprudente, que fere o princípio da não-maleficência ao praticar um ato cirúrgico, mesmo inédito, para o qual não estava preparado. Conhecimento prévio de anatomia, fisiologia, patologia, entre outras, é fundamental para o sucesso de qualquer procedimento. A serendipidade é um evento raro na medicina. E neste ponto precisa-se discordar de alguns livros que contam a história da cirurgia como se tudo fosse devido ao acaso. A medicina e a cirurgia têm um passado glorioso e honrado. As descobertas são frutos de muito esforço, disciplina, estudo e raramente são devidas à sorte.

A coragem é uma força de espírito, uma condição necessária às outras virtudes: o agir com lucidez. Na medida em que o sofrimento é o pior dos sentimentos (pior que o medo e a morte), é preciso muita coragem para enfrentá-lo.

Winston Churchill foi bastante claro em reconhecer o valor desta virtude. Para ele "a profissão da medicina e da cirurgia deve sempre se posicionar como a mais nobre que o homem pode adotar. O espetáculo de um médico em ação entre soldados em igual perigo e com a mesma coragem, salvando vidas quando todos os outros as estão tirando, aliviando a dor quando todos os outros a estão causando, deve sempre parecer glorioso, seja para Deus ou para o homem"11.

Acima de tudo a coragem é importante para o cirurgião. Não é qualquer um que, tendo conhecimento e oportunidade, teria ímpeto para inovar ou improvisar durante um ato operatório. A história mostra claramente isto: cirurgiões obstinados, de bom coração e cuja coragem mudou os rumos da profissão.

Parafraseando Alcebíades, general romano: não é a força que produz a vitória, mas a sua aparição. Um cirurgião habilidoso manipula mais que pinças, manipula percepções. Sua entrada, às vezes triunfal, e sua presença imponente estão imbuídas de coragem, talvez sua virtude principal.

\section{Compaixão}

Assim como a coragem toma posição pelo outro, a compaixão toma posição com o outro ${ }^{3}$. E isso significa não apenas sofrer dores em si mesmo, mas participar das dores alheias. "Quando o coração desperta e transita do egoísmo bestial para a verdadeira humanidade, aí se dá a compaixão"7. É isto o que significa o termo, literalmente sofrer com: "... Pois quem suportaria o açoite e o escárnio do tempo, / a maldade dos opressores, a arrogância dos orgulhosos, / a tortura do amor frustrado, a ineficácia das leis, / a insolência do poder e o desprezo que vence a paciência ..."12

É a compaixão que nos impele sem refletir, a levar alívio aos que sofrem. A compaixão pode ser observada no cirurgião à cabeceira do doente, na compreensão dos fatores pessoais e afetivos envolvidos durante o ato operatório: "o médico às vezes cura, frequentemente alivia, consola sempre" 9,13. Thomas Sydenhan claramente expressou a importância do cuidado com os doentes afirmando que devemos cuidar do enfermo com ternura e lembrar-nos de ser o companheiro de sofrimento deles ${ }^{9}$.

Notoriamente o cirurgião transparece confiança em seu julgamento e este não pode estar divorciado da capacidade de se colocar na posição do paciente. A alteridade é componente indispensável no entendimento da dor de nosso semelhante. Por mais que a relação médico-paciente esteja abalada nos tempos modernos, compaixão e tecnologia não são incompatíveis, "podem se reforçar mutuamente" ${ }^{4}$. É preciso, entretanto, entender e diferenciar a compaixão da piedade e da misericórdia.

Diz-se que o cirurgião é cruel porque corta a carne sem pena. Ledo engano! O cirurgião sofre junto, mas aquele que opera não deve lamentar, e sim agir. O sofrimento que ele deliberadamente promove, a dor que ele causa, tem uma finalidade, um propósito. Não é piedade, pois esta é passiva. É compaixão, pois decorre da ação de tentar ajudar.

Compaixão é um amor entristecido. Não se resume a um sentimento, mas a uma disposição, e é esta a virtude do cirurgião. É uma afeição que implica em ter a capacidade de sentir. Assim como uma operação bem sucedida, consiste em esforço e excelência e atesta o valor do ser humano" 3 .

A prática cirúrgica transcende o tecnicismo, é ciência guiada não somente pelas mãos, mas também pelos corações e mentes dos médicos. O ato cirúrgico representa muito mais do que atuar em hospitais, ambulatórios e enfer- 
marias, traduz a certeza de que o saber científico não está encerrado em si mesmo. Ser cirurgião é ser capaz de levar conforto e alívio ao ser humano debilitado pela doença, fazendo da técnica um caminho entre o médico e paciente.

David Hume, em seu Tratado da Natureza Humana (1738), diz que: "Nenhuma qualidade da natureza humana é mais importante, quer por si, quer por suas consequências, do que a propensão que nós temos para simpatizar (compadecer) uns com os outros, para receber por comunicação seus sentimentos e suas disposições, por mais diferentes que sejam dos nossos, e até mesmo contrários..."14.

Quão importante é a participação dos outros, notadamente dos médicos e cirurgiões, na dor alheia, traduzindo uma compaixão na forma de evitar a solidão do sofredor: "... quem sofre sozinho, sofre muito mais em sua mente. / Deixa para trás a liberdade e a alegria. I Mas a mente com muito sofrimento pode superar-se. / Quando a dor tem amigos e suportam a sua companhia, / Quão leve e suportável, a minha dor parece agora..."15.

\section{CONCLUSÃO}

Em todo trabalho cirúrgico o que está em jogo é a vida: o cirurgião se coloca entre a doença e a morte. Retórica, disciplina, imanência, temperança, polidez, desprendimento, perseverança, trabalho, metodicidade, liderança, amizade, lealdade, justiça, humildade, alteridade, simplicidade. Virtudes reconhecidamente importantes à formação moral de qualquer ser humano. Costuma-se afirmar que não vemos o mundo como ele é, mas como nós somos. Na verdade vemos o mundo como nos ensinaram, e, por isso, o professor de cirurgia tem tanta importância. Ele ensina estas qualidades as demonstrando aos seus discípulos. Gostamos quase que incondicionalmente destes docentes, não porque eles sejam perfeitos, nem tanto pelos seus feitos médico-cirúrgicos, mas pelo seu caráter, coragem, compaixão e tolerância. A oportunidade de aprender com eles é um privilégio e uma honra.

\section{A B S S T R A C T}

Interactions among human beings are very complex. Using only an ethical code as reference to deal with moral conflicts is hardly ever enough. Responsibility ethics demand such a profound reflection as well as a discussion about human essence and its role in society. The responsibility of a surgeon is inherent in a profession based since its origin, not only on altruism and humanity, but also on compassion, courage and tolerance. The studies and the comprehension of these qualities as well as the transmission of these values to the students and to the surgery residents are essential for human education of these individuals. This essay offers to show that these essential virtues are strongly connected to the work the surgeon develops whereas his/her responsibility starts before the surgery - when one intends to act.

Key words: Education, medical. Codes of ethics. Personality. Morale. Virtues.

\section{REFERENCIAS}

1. Reason J. Human error: models and management. BMJ. 2000;320(7237):768-70.

2. Brennan TA, Leape LL, Laird NM, Hebert L, Localio AR, Lawthers $A G$, et al. Incidence of adverse events and negligence in hospitalized patients. Results of the Harvard Medical Practice Study I. N Engl J Med. 1991;324(6):370-6.

3. Comte-Sponville A. Pequeno tratado das grandes virtudes. São Paulo: Martins Fontes; 2004. Tradução de Eduardo Brandão.

4. Gawande A. Complicações: dilemas de um cirurgião diante de uma ciência imperfeita. Rio de Janeiro: Objetiva; 2002. Tradução Ana Deiró.

5. Gleiser M. Micro Macro. Reflexões sobre o homem, o tempo e o espaço. São Paulo: Publifolha; 2005.

6. Bullfinch T. O Livro de ouro da mitologia. História de deuses e heróis. Rio de Janeiro: Ediouro; 2000. Tradução David Jardim Júnior.

7. Campbell J. O poder do mito. $20^{\mathrm{a}}$ ed. São Paulo: Palas Athena; 2002. Tradução de Carlos Felipe Moises.

8. Jorge Filho I. Os compromissos do médico: reflexões sobre a oração de maimônides. Rev Col Bras Cir. 2010;37(4):306-7.

9. Costa ML. Estórias da história da medicina. $2^{a}$ ed. Belo Horizonte: Coopmed; 1999.

10. Ellis H. Operations that made history. London: Greenwich Medical Media; 1996.
11. Gordon R. Os grandes desastres da medicina. $2^{\text {a }}$ ed. Rio de Janeiro: Ediouro; 1997.

12. Harvey J. Homens de preto. São Paulo: Unesp; 2003. Tradução Fernanda Veríssimo.

13. Rezende JM. À sombra do plátano. Crônicas de história da medicina. São Paulo: Unifesp; 2009.

14. Hume D. Tratado da natureza humana. São Paulo: Unesp; 2001. Tradução de Déborah Danowski.

15. Shakespeare W. The complete works. Oxford: Clarendon; 1991.

Recebido em

Aceito para publicação em

Conflito de interesse: nenhum

Fonte de financiamento: nenhum

\section{Como citar este artigo:}

Soares Júnior C, Gomes CA, Peixoto RO, Soares FPTP. Tolerência, coragem e compaixão: virtudes cardinais do cirurgião. Rev Col Bras Cir. [periódico na Internet] 2012; 39(2). Disponível em URL: http:// www.scielo.br/rcbc

Endereço para correspondência:

Cleber Soares Júnior

E-mail: cleberdoc@ig.com.br 